\title{
Amino acid analysis of planarians following conditioning ${ }^{\prime \prime 2}$
}

\author{
F. T. Crawford and F. J. King, FLORIDA STATE UNIVERSITY \\ Lynne E. Siebert, NORTH CAROLINA STATE UNIVERSITY
}

\begin{abstract}
Four groups from a study of partial reinforcement effects upon classically conditioned planarians were subjected to amino acid analysis. Results of the amino acid analysis were found to have significant correlations with behavioral measures.

Problem

Current interest in the biochemical bases of learning is producing an ever increasing amount of research. The use of amino acid analysis in another area led us to consider whether or not a similar analysis could be made upon planarians.

\section{Method}

The Ss were four subgroups of five Ss each from a larger group used in an investigation of partial reinforcement effects upon classically conditioned planarians. The Ss were equated as nearly as possible for size. Group I received eight light and eight shock presentations which were paired. Group II also received eight light and eight shock presentations, but they were unpaired. Group III was given four paired light and shock presentations plus four additional light presentations. Group IV received eight light and four shock presentations, none of which were paired. On paired treatments light was presented for $3 \mathrm{sec}$. with shock occurring during the final second. The intertrial interval was $30 \mathrm{sec}$. On unpaired treatments light was presented for
\end{abstract}

3 sec. and $30 \mathrm{sec}$. later $1 \mathrm{sec}$. of shock was given. The interval between blocks of trials was $24 \mathrm{hr}$., and each $\mathrm{S}$ received a total of 15 blocks of trials. After a $24 \mathrm{hr}$. interval, extinction trials of eight light presentations were given each day for four days.

Following conditioning an amino acid analysis was conducted on each S. The Ss were placed 2 in apart on $111 / 2$ in by 18 in Whatman No 1 chromatography paper and allowed to dry. One dimensional analyses were carried out using the techniques reported by Williams (1951). The solvent for the analyses was butanol-acetic acid-water. Six colored spots were developed with a ninhydrin solution, and their densities read with a Welsh densitometer.

\section{Results}

The behavioral data of the $20 \mathrm{Ss}$ are shown in Fig. 1. Analysis of variance of the acquisition data with the 15 daily blocks grouped into five blocks of three days each shows a significant block by pairing condition interaction $(\mathrm{F}=7.11 ; 4,64 \mathrm{df})$. No difference due to type of reinforcement was observed, but the curves do separate in the expected direction. An analysis of variance of the extinction scores, adjusted for terminal acquisition level, shows a significant pairing by reinforcement interaction ( $\mathrm{F}=4.93 ; 1,48 \mathrm{df}$ ) with the $100 \%$ paired group extinguishing more rapidly than the $50 \%$ paired group

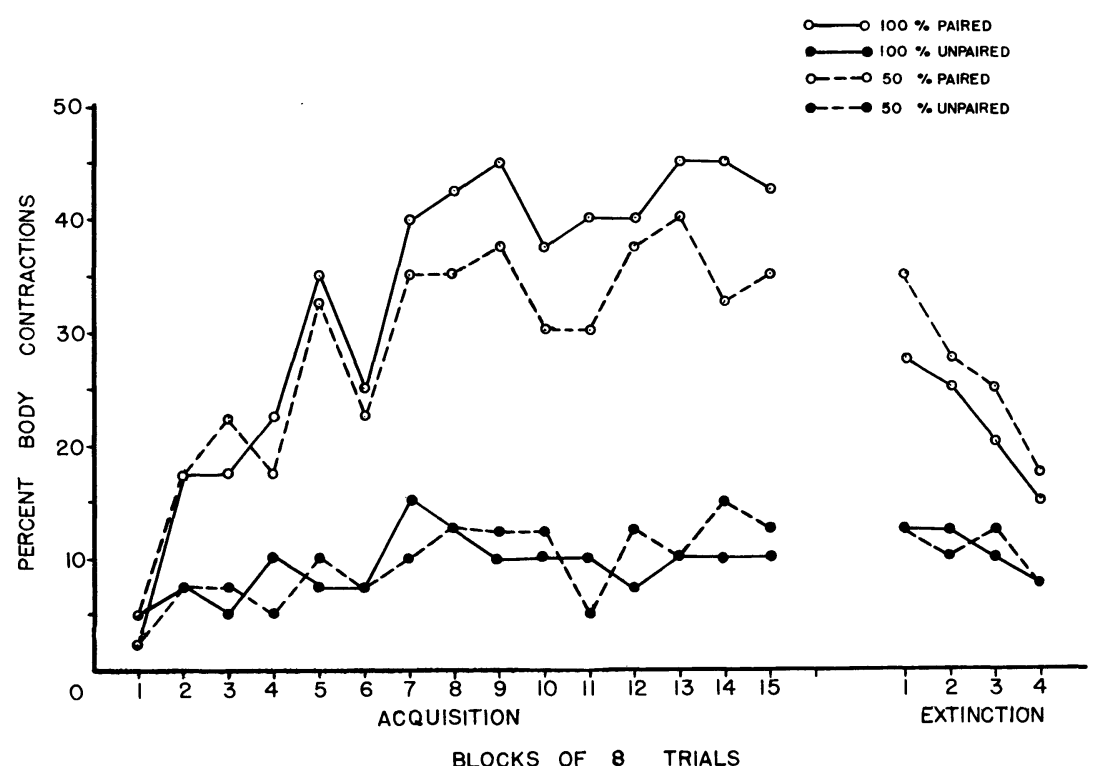

Fig. 1. Percent conditioned responses (body contraction) to light presentation. 
but with no difference between the $100 \%$ and $50 \%$ unpaired groups.

The six amino acid spots were correlated with scores for the five acquisition blocks and the four unadjusted extinction blocks. Spot No. 1 had significant correlations with extinction blocks three and four $(.52, .58)$; spot No. 2 had a significant correlation with extinction block three (.47) and an almost significant correlation with extinction block four $(.43, .44=.05$; df, 18); spot No. 3 had significant correlations with acquisition blocks two, three, four, and five $(.63, .51, .46, .46)$ and with extinction blocks three and four $(.48, .48)$. One dimensional paper chromatography does not permit each amino acid to be separated from the others; consequently, the exact composition of the spots is unknown. However, it is likely that spot No. 1 contains cysteine, cystine and lysine; spot No. 2, histidine, arginine and asparagine; and spot No. 3, glutamine, aspartic acid, citrulline, serine, methionine sulfoxide, glycine and taurine. Diseussion

While the interpretation of the significant correlations is uncertain, three possibilities are apparent. First, individual differences in amino acid makeup have a direct influence on conditionability and resistance to extinction regardless of treatment. Second, treatments influence metabolic composition as well as behavior in the planarians. Analysis of variance revealed a significant difference for pairing conditions in spot No. 3 ( $F=4.69 ; 1,16 \mathrm{df})$. However, neither treatment nor interaction effects were significant for the other five spots. The third interpretation, of course, is that a third variable related to both behavior and metabolism is the source of the significant relationships. Further investigations of these variables in planarians are needed to determine whether any or all of these interpretations are most plausible.

\section{Reference}

WILLIAMS, R. J. (Ed.) Biochemical institute studies IV. Univ. of Texas Publication No. 5109, 1954.

\section{Notes}

1. This research was partially supported by a grant from the Florida State University Research Council.

2. The statistical analyses were made possible in part by an NSF Grant (No. GP671) to the Florida State University Computation Center. 